\title{
EVALUATION OF POST-BARIATRIC ABDOMINOPLASTY RESULTS WITH TRADITIONAL OR NEO-UMBILICOPLASTY BY PLASTIC SUR- GEONS AND PATIENTS
}

\author{
Maria Gabriela B. Vallim (IC), Davi Reis Calderoni (PQ), Paulo Kharmandayan(PQ)
}

\section{Summary}

Abdominoplasty procedures have been proven highly valuable in promoting better quality of life, hygiene and self-esteem to post-bariatric surgery patients. Plastic surgery literature reveals that the aspect of the navel is one of the most problematic issues regarding surgical results and, because of that, many different surgical techniques have been proposed aiming to obtain a satisfactory outcome. However, little is known about patients' preferences of these different techniques and their results. The aim of the present study was to analyze and compare the evaluations made by plastic surgeons and patients of the results of two different techniques - traditional and neo-umbilicoplasty with lateral flaps.

Keywords: Abdominoplasty, navel, results

\section{INTRODUCTION}

Bariatric surgery is considered to be the most effective treatment of morbid obesity. However, post-operative massive weight loss usually result in skin excess, especially in the breasts, proximal limbs and the abdomen, causing significant discomfort to the patients. Abdominoplasty procedures permit, besides the reduction of excess skin, an improvement in navel appearance.

Several umbilicoplasty techniques have been proposed over the time. They can be basically divided in two groups: umbilicoplasty with the preservation of the native navel or neoumbilicoplasties, with surgical recreation of the navel.

The aim of the present study was to compare the evaluation of surgical results by plastic surgeons and pre-abdominoplasty patients of two different techniques of navel treatment. Also, we sought to identify which aspect was considered to be more important to the patients in the appraisal of surgical results.

\section{RESULTS AND DISCUSSION}

Five plastic surgeons randomly analyzed postoperative pictures of 54 cases of post-bariatric Abdominoplasties operated between 2008 and 2013, from which 35 were submitted to the traditional umbilicoplasty and 19 were treated with the lateral flaps neo-umbilicoplasty technique currently performed at the UNICAMP Hospital. The pictures were then evaluated by 50 patients awaiting for a post-bariatric Abdominoplasty.

Statistical analysis showed that surgeons gave significantly higher grades to navels treated with the neo-umbilicoplasty technique $(\mathrm{OR}=22,3$ $; p<.0001)$. The patients' grades showed no differ- ence with regard to the employed technique $(p=0,0624)$.

When asked about which aspect of the surgery was considered by them to be the most relevant in determining a good abdominoplasty result, only $4 \%$ of the patients chose the "aspect of te navel". The points elected by the majority of the patients as paramount for a good result were "skin excess" (48\%) and "scar aspect" (36\%) (Figure 1).

Figure 1. Aspect considered as the most important for the patients to a successful outcome of abdominoplasty.

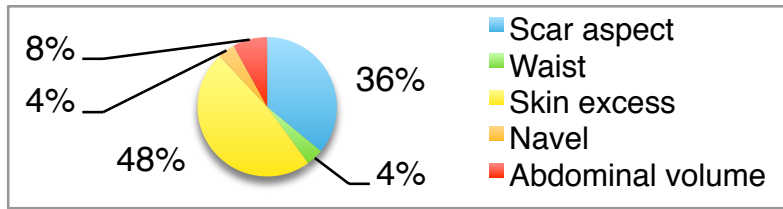

\section{CONCLUSION}

The results showed that the patients did not attribute better results to any specific technique, although surgeons did observe better navel aspect in patients treated with neo-umbilicoplasty.

Navel aspect had a secondary importance to the patients when analyzing the results of postbariatric abdominoplasties.

\section{ACKNOWLEDGMENTS}

I'm sincere grateful to my supervisor Dr. Davi Reis Calderoni for the motivation, and immense knowledge; and I'm also thankful to PIBIC/SAE, for financial support.

\footnotetext{
1-Oliveira V, Linardi R, Azevedo A. Rev. Psiquiatr.Clin.2004;31(4):199-201

2-Reno BA, Mizukami A, Leme de Calaes I. Rev. Bras. Cir. Plást. 2013 Jan-Mar; 28(1).

3. Junior EM. Editora Atheneu. Capítulo 14.Pag 127-142.
} 